\title{
The role of university research centers in promoting research
}

\author{
V. Kumar $^{1}$
}

Published online: 25 April 2017

(C) Academy of Marketing Science 2017

As businesses evolve, our understanding of them also continues to evolve. A key factor for this evolving understanding has been the impact of ongoing meaningful research. The significant evidence-based knowledge created through academic research in marketing and related fields has clearly demonstrated to organizations valuable insights for managing their businesses. Research has demonstrated that managing based on legacy approaches, intuition, or organizational snapshots imposes costs and substantial risks on the organization. As a result, evidence-based knowledge creation, the forte of academic scholars at universities worldwide, continues to be essential. This focus on university research has spurred the creation of research centers, with many dedicated to specialty areas of attention. I have been fortunate to have led two major research centers over the last two decades, and hence I gladly accepted the invitation to write about the purpose, benefits, and the functioning of research centers. I outline my experience with setting up and managing research Centers as a case study to aid others in this ever increasing popular addition to marketing departments.

Based on the experience of setting up both the ING Center for Financial Services at the University of Connecticut in 2001 and the Center for Excellence in Brand and Customer Management (CEBCM) at Georgia State University in 2008, in this article I would like to discuss the general structure of a research center that can serve as a platform to all the relevant stakeholders in accomplishing their goals. Established with an international, and most importantly, an interdisciplinary

V. Kumar

vk@gsu.edu

1 Center for Excellence in Brand and Customer Management, Georgia State University, Atlanta, GA, USA scope, the Center aims to advance the knowledge and practice of modern evidence-based management and to foster impactful research. The creation of these centers was the result of a careful study of the evolving business atmosphere and its critical needs.

At the earliest stages, in a business world dominated by manufacturing, we understood that businesses existed for the purpose of managing hard assets such as factories and company infrastructure. With the increasing migration of focus on services and the management of intellectual property across the world, the management of intangible assets has become crucial for the efficient functioning and development of businesses. In this constantly evolving space, customers and brands have emerged as the ultimate intangible assets.

Today, more and more organizations are recognizing the importance of managing brands and customers simultaneously. Research has identified customers and brands to be of vital importance to long term sustenance of businesses (Aaker 1991; Berger et al. 2002; Blattberg et al. 2001; Gupta and Lehmann 2003; Morgan and Rego 2009). One of the most anticipated innovations in the marketing area has been the ability to link investments in branding to customer profitability (Kumar et al. 2016). Rigorous quantitative analysis for successful brand and customer management has become the foundation for all businesses. The case for advanced quantitative analytics has been made possible by the substantial growth of computing power and storage space. Taking into account the cognizance of these changing needs as well as business conditions, CEBCM was created with a primary focus on the management of customer and brand value with an interdisciplinary perspective.

At the time of CEBCM's inception, the combination of managing brand and customer value through the interaction of various disciplines was a radically new concept in the context of an academic setting. Pioneering such an agenda, the 
Center lends itself to contributions in research, teaching, and service to both the academic and the business communities. To achieve these expectations, the Center relies upon five important elements that are essential for a successful research center: structure, people, process, dashboard metrics, and financial support. The rest of this article will expound upon of each of these elements, providing an example for the successful establishment of other research centers.

\section{Structure}

In terms of organizational structure, the Center reports to the Dean of the Business School (Robinson College of Business) and is composed of faculty members and doctoral students in marketing, support staff, and graduate assistants. The Center is led by the Executive Director, assisted by the Assistant Director, and significantly benefits from the leadership of the Department Chair in the Marketing Department. The doctoral students and visiting scholars work with faculty members to drive the research output at the Center. The Center also enjoys the support of a distinguished set of faculty members and marketing practitioners who form the advisory board, as well as the President and Provost of GSU. All of the faculty members of the advisory board are chaired professors in Business and Marketing at various premier educational institutions around the world. The marketing practitioners belong to leading organizations and provide a real-time business perspective to the cutting-edge research at CEBCM.

In terms of research structure, an interdisciplinary approach drives a successful research center. For CEBCM, we have observed that insights from other disciplines-such as the geosciences, epidemiology, risk management, management, statistics, finance, and international business - can also offer crucial insights into our key research problem of optimizing the value of brands and customers for an organization. For instance, when a customer's brand value and lifetime value is computed, the risk/uncertainty associated with realization of future cash flows of customers living in various geographic areas within a country and across countries have to be incorporated. Further, the growth in the cash flows is modeled through epidemiological models. These models are estimated through the most rigorous statistical methods. The predicted future cash flows are then discounted to net present value using information from finance. As a result, what emerges is an interdisciplinary approach to studying brands and customers that provides the most complete picture. Keeping in line with these cross-disciplinary influences, the Center continually strives to, at the minimum, incorporate such learning into ongoing marketing investigations to obtain a holistic understanding of customers and brands.

\section{People}

Whereas the research output at a research center is primarily driven by the faculty members, visiting scholars, and doctoral students, the support personnel are also vital. At most research centers, four types of support staff are key to efficient functioning. First, a center administrator is critical in running a research center. This person will typically coordinate the daily operations, support all entities involved in the center, and manage interactions of the center with the other constituents of the department/university and external vendors. Second, a research coordinator is needed to manage and coordinate all research projects at the center. This would ideally include identifying research needs, coordinating project activities, and generating and delivering reports. In addition, this member can also aid in disseminating research findings via journals, trade-related publications, and books, assist in all writing initiatives at the center, and explore new research opportunities that will keep the research pipeline of the center in steady flow. Third, a project coordinator who can interact with business community members will be helpful for the center. Ideally, this member will liaise with the business community to bring in potential clients, attend exploratory research meetings, develop research proposals, help kick start a research project, and compile final reports to be delivered to the clients. Finally, a technology coordinator can be helpful in keeping the center in good form by overseeing the technology aspects. Ideally, this member can attend to all the technical needs of a center such as hardware/software procurement and maintenance, programming/coding support as necessary, and server maintenance and upkeep. With key support from the college of business and the university, CEBCM benefits from the contributions of all these types of support staff.

\section{Process}

The goal of a research center is to enable interaction between faculty, scholars, students, and industry to enhance research opportunities, academic excellence, real-world problem solving, and knowledge creation and dissemination. This interaction is facilitated by the Executive Director. Specifically, the overarching goal at CEBCM is to advance the art, science, and practice of learning and teaching as it pertains to the unique aspects of managing brands and customers. The integration of knowledge from other relevant disciplines warrants the most sophisticated statistical knowledge to produce useful and cutting-edge knowledge. To facilitate research productivity, CEBCM ensures that each faculty member engages with multiple doctoral students, and each doctoral student engages with multiple faculty members (see Fig. 1). This creates an atmosphere replete with the healthy exchange of ideas which results in a fertile research environment. 
Fig. 1 CEBCM's research dynamic

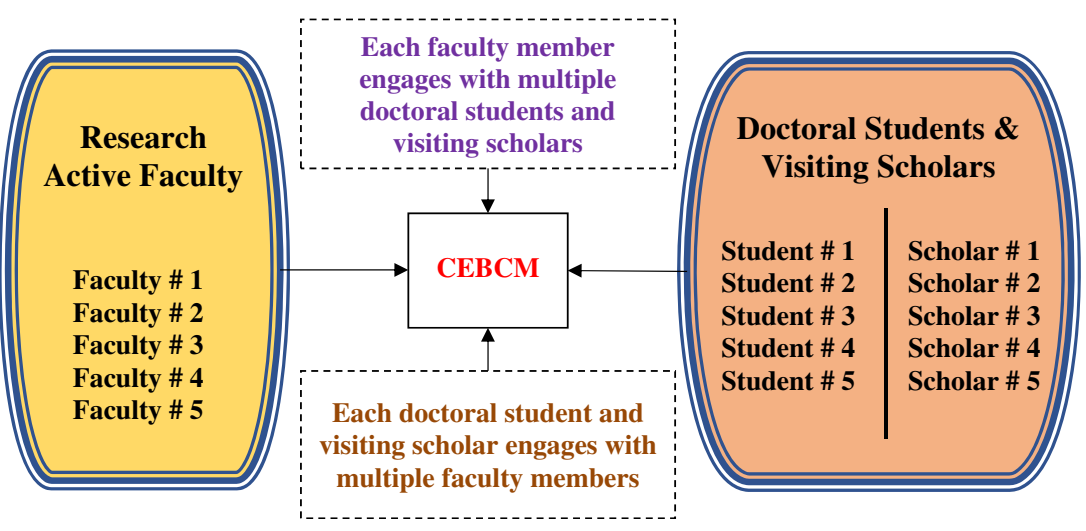

As is evident, the level of interaction at the Center is highly involved and operates at the highest level of efficiency. The various entities at CEBCM come together to function successfully in five key areas, serving as an example for the formation of other research centers in terms of custom research, embedded research, thought leadership, certificate programs, and executive education.

\section{Custom research}

Research centers must constantly look for new areas to shed light on and bring to the attention of the academic community, with a focus on rigor, relevance, and actionable implications. For example, CEBCM's primary agenda is to produce cuttingedge, pioneering research insights on managing customers and brands that significantly contribute to the body of marketing knowledge and advance the discipline. In terms of rigor, we ensure that every research venture (subject to its scope) is empirically, conceptually, and analytically rigorous. This means that not only are the empirical studies rigorous in their approach, but also the conceptual and analytical studies. This makes the faculty associated with CEBCM known for their rigorous research, and produces future research scholars with a rigor-oriented research acumen. CEBCM also ensures that all research studies address the most relevant managerial problems and propose the most appropriate and actionable method. This includes (but is not limited to) (a) solving unique and relevant managerial problems that have received little or no research attention, (b) advancing the theoretical and/or conceptual principles that are also accessible to the practitioner community, and (c) questioning the conventional wisdom and creating new research stream(s).

\section{Embedded research}

To produce a relevant study that is also of use to managers, researchers must conclusively answer the "What's in it for me?" questions from the practitioners' perspective. This secures the practitioner's attention while solving a relevant marketing issue. This involves interacting and engaging with the business community to identify their challenges, and exploring novel insights to solve them. While the insights that we uncover through such ventures serve as unique solutions to the specific businesses we interact with, the overall learning and understanding will be shared with the larger academic/practitioner community through relevant publication outlets.

\section{Thought leadership}

The culmination of all research initiatives from a research center is dissemination of knowledge through one or more outlets such as (a) publishing in premier scholarly journals and trade-related magazines, (b) publishing books, book chapters, and monographs, (c) organizing academic/practitioner conferences, (d) holding seminars for both faculty and doctoral students, and (e) offering workshops for research scholars and managers. Conferences conducted by research centers should bring together both academic scholars and practiceleading professionals to present and examine the latest new concepts and applications of evidence-based management. Besides the sharing of concepts and developments, these conferences create opportunities for continuing collaboration, yielding a wide array of benefits to both sides. Examples of such initiatives include CEBCM's involvement in hosting the Theory + Practice in Marketing conference in June 2015, and AMA Knowledge Development Coalition Conference in July 2008, where the AMA Marketing Knowledge Series book Marketing Mix Decisions: New Perspectives and Practices was released. Besides conferences focused on breakthrough developments and research collaborations, CEBCM demonstrates how research centers can also disseminate knowledge by organizing regular workshops where practitioners can learn best practices in evidence-based management of brands and customers so that they can apply these concepts in their own organizations. Also, while many schools offer doctoral degrees and some offer training in general marketing, few can offer high-level and up-to-date courses in this area. In this regard, CEBCM hosts seminars for both faculty and doctoral students from around the world, who can apply these concepts and take 
this training back to their home institutions. Additionally, CEBCM hosts leading researchers and invites them to deliver seminars to doctoral students, offer classes, and establish and advance research collaborations. These visits help CEBCM stay at the forefront of cutting edge research on evidencebased management. Also, it exposes GSU students and research faculty to the state-of-the-art research concepts and methodologies used around the world.

\section{Certificate program}

Apart from publishing research insights, research centers can also disseminate the knowledge generated via a certificate program. At CEBCM, the Certificate of Specialization in Brand and Customer Management focuses on creation and management of profitable long-term relationships with customers. This program consists of four modules: Marketing Research, Direct and Database Marketing, Customer Relationship Marketing, and Product and Brand Management. The emphasis of this certificate program is on the use of information and communication strategies in researching, selecting, entering, and competing in global markets. Upon successful completion of these four modules, students are awarded a Certificate of Specialization in Brand and Customer Management. The concepts and skills taught in the certificate program cover strategic business models for relationship marketing, the acquisition and retention of profitable customers through direct and interactive techniques, and the use of appropriate multichannel communications for creating higher profits for the firm and higher degrees of customer loyalty and customer satisfaction among the profitable customers.

\section{Executive education}

Finally, research centers can disseminate knowledge by engaging with the business community through teaching initiatives such as executive education programs. CEBCM's executive education programs such as the Certificate Program in Marketing and Branding are designed to be fast-paced and highly-interactive, focusing on the creation and management of profitable relationships with customers by building brand equity. The sessions emphasize the use of information and communication strategies in researching, selecting, entering, and competing in global markets. This program is engineered for participants to discover new approaches to the development of strategic business models for relationship marketing, the acquisition and retention of profitable customers through direct and interactive techniques, and the use of appropriate multichannel communications for creating higher profits for the firm and higher degrees of customer loyalty and customer satisfaction among the profitable customers.
The program content is designed and taught by awardwinning professors who have extensive experience in teaching marketing to working professionals. The program consists of six topics: Business Intelligence, Database Marketing, Brand Management, Profitable Customer Engagement, Digital and Social Media Marketing, and Innovation, Interaction, Integration, and Implementation. Upon successful completion of these six topics, participants are awarded a Certificate in Marketing and Branding. The overarching goal is to help participants deal with any real-world business challenge in the domain of marketing and branding after successful completion of this program. This unique certificate program covers all of the tools, concepts, application and integration for a successful career in marketing and branding.

\section{Dashboard metrics}

Possibly the simplest yardstick of a research center's productivity would be the contributions in terms of research and implementation within the domain, stemming from its ability to generate a continual stream of research ideas, newer methodologies and techniques, strategies and solutions. The example of CEBCM's dashboard of metrics offers an approach for other research centers to consider.

CEBCM's research on newer, more innovative and efficient methodologies has resulted in a rich accumulation of marketing techniques and research frameworks. In this regard, the faculty members associated with CEBCM have a growing list of contributions to marketing that continues to be influential in fostering a number of much-needed paradigm shifts. Further, the research findings and theories developed at CEBCM have often questioned the conventional logic, in addition to advancing the thought leadership in this area for the academic world. Apart from being published in academic publications, many of CEBCM's research insights have also investigated specific marketing problems of various B2B and B2C companies. Some of these models that were developed and implemented as solutions to these problems have resulted in multi-million dollar gains for the companies.

Faculty members and doctoral students associated with CEBCM have brought worldwide acclaim to the Center for its pioneering work in the area of brand and customer management. With its research driven by rigor and relevance, $\mathrm{CEBCM}$ continues to contribute to the growing knowledgebase of the academic community, while also ensuring that the impact of academic research gets duly communicated to the industry. As a result, contributions to marketing from the members associated with CEBCM have therefore won numerous awards and accolades, and continue to do so (see Fig. 2). 
Fig. 2 Dashboard metrics at CEBCM

1. TOTAL JOURNAL PUBLICATIONS

$>$ Total journal publications by Faculty

Total journal publications by Students and Visiting Scholars

2. TOTAL PUBLICATIONS IN TOP JOURNALS

$>$ Total publications in top journals by Faculty

$>$ Total publications by in top journals by Students and Visiting Scholars

\section{AWARDS/ACCOMPLISHMENTS}

Awards/Accomplishments won by Faculty

> Awards/Accomplishments won by Students and Visiting Scholars

Typical Awards/Accomplishments won by Faculty

Regent's Professor | Teaching Excellence

Awards | Best Professor Awards |

Professor of the Year Awards | ISMS-

MSI Practice Prize Awards | Sheth

Foundation Awards | Best Paper Awards

| Research Grant Recipients
Typical Awards/Accomplishments won by Students and Visiting Scholars Teaching Excellence Awards | ISMS-MSI Practice Prize Awards | Best Paper Awards | Research Grant Recipients | ISMS Doctoral Consortium Fellows | AMA-Sheth Foundation Doctoral Consortium Fellows | ISBM PhD Student Camp for Research Fellows | ISMSMSI Practice Prize Competition Finalists

\section{Financial support}

The success of a research center relies heavily on its financial well-being. Given that the goal of a research center is to conduct research and expand the knowledge base in a safe and secure environment that includes financial stability and security, financial support is critical for its growth and success. Research centers typically receive financial support from one of three sources: endowments, university funding, or self-funding through consulting projects.

First, the center can seek an endowment, and thus become an endowed research center such as the ING Center for Financial Services. The endowment will then fund the center through the period of funding. This is an ideal setting for any research center, as the financial needs are typically taken care of. This implies that the focus can solely be on exploring research opportunities and contributing to the body of knowledge, without having the pressure to raise funds for its continued existence. In such a setting, it is important that the center not take the assured funding for granted, but be focused on expanding the knowledge base.

Alternatively, the university could provide the funding for the center, as is the case for CEBCM. This reflects the commitment of the university to foster a research-oriented learning environment, and it is a valuable option to attract promising talent to the university by way of faculty and students. In effect, this option delivers a great value proposition for the university, and is bound to bring in an impressive return on investment.

Finally, the center can be self-funded by raising funds through consulting projects to pay for its existence and regular functioning. Essentially, this would render a consulting firmlike setup for the research center. This type of setup can be the most demanding one for a research center to conduct meaningful research, as it involves having to also focus on being financially sustained. This could also make the growth of the center "episodic" whereby only new funds would spur development. As a result, this is likely to be the least preferred state for any research center.

\section{Conclusion}

As an example of the potential benefits of a research center, CEBCM's focused research environment, coupled with an interdisciplinary outlook toward research, has produced several research collaborations, and continues to do so. This has not only produced impactful research that has advanced the body of knowledge in marketing, but also has advanced the reputation of Georgia State University in its pursuit towards fostering a research-oriented learning environment. Additionally, the high quality of research output has secured rewarding careers with organizations and universities worldwide for the doctoral students and graduate students associated with CEBCM.

I believe that the five elements discussed in this article have immensely helped in establishing CEBCM as a worldwide leader in evidence-based management of brands and customers, and can in turn help other research centers do the same. In my opinion, when a research center has a significantly positive impact not only in its focal area of interest, but also on its surrounding constituents and its environment, the role of the center can be considered to be gainfully served. In this regard, CEBCM can serve as an example for the establishment of other research centers. 
Acknowledgments The author thanks the assistance of Bharath Rajan in the preparation of this manuscript. The author owes additional thanks to Renu for copyediting this manuscript. V Kumar is also been honored as the Chang Jiang Scholar, Huazhong University of Science and Technology, China; TIAS Fellow, Texas A\&M University, College Station, TX; and ISB Senior Fellow, Indian School of Business.

\section{References}

Aaker, D. A. (1991). Managing brand equity. New York: The Free Press. Berger, P. D., Bolton, R. N., Bowman, D., Briggs, E., Kumar, V., Parasuraman, A., \& Terry, C. (2002). Marketing actions and the value of customer assets a framework for customer asset management. Journal of Service Research, 5(1), 39-54.

Blattberg, R. C., Getz, G., \& Thomas, J. S. (2001). Customer equity: building and managing relationships as valuable assets. Harvard Business Press.

Gupta, S., \& Lehmann, D. R. (2003). Customers as assets. Journal of Interactive Marketing, 17(1), 9-24.

Kumar, V., Luo, M., \& Rao, V. R. (2016). Linking an individual's brand value to the CLV: An integrated approach. Atlanta: Working Paper, Georgia State University.

Morgan, N. A., \& Rego, L. L. (2009). Brand portfolio strategy and firm performance. Journal of Marketing, 73(1), 59-74. 